What initially seems to be a democratic or "liberal" stance in awarding all the same access to healthcare technology could in actuality be a conservative and medically radical solution to the social inequalities that have led to an increase in caesarean section rates. Additional research is needed in settings where the economically based distribution of caesarean sections is not as discrepant as in Brazil. Even modest inequalities in healthcare provision might create a market for unnecessary interventions among women who feel marginalised from access to medical technology.

Contributors: see bmj.com

Funding: Funding for this study was provided by the European Community, the Fulbright Foundation (for DPB), and the Programa de Apoio a Núcleos de Excelência of the Brazilian government.

Competing interests: None declared.

1 Belizan J, Althabe F, Barros F, Alezander S. Rates and implications of caesarean sections in Latin America: ecological study. BMJ 1999;319:1397 402.

2 Barros F, Victora C, Morris S. Caesarean sections in Brazil. Lancet 1996;347:839.

3 World Health Organization. Appropriate technology for birth. Lancet 1985;2:436-7.

4 Ash A, Okah D. What is the right number of caesarean sections? Lancet 1997;349:1557.

5 Al-Mufti R, McCarthy A, Fisk N. Obstetricians' personal choice and mode of delivery. Lancet 1996;347:544.

6 Geary M, Wilshin J, Persaud M, Hindmarch P, Rodeck C. Do doctors have an increased rate of caesarean section? Lancet 1998;351:1117.

7 Murray S, Pradenas F. Health sector reform and rise of caesarean birth in Chile. Lancet 1997;349:64

8 Haines A. Health care in Brazil. BMJ 1993;306:503-6.

9 De Mello e Souza C. C-sections as ideal births: The cultural construction of beneficience and patients' rights in Brazil. Cambridge Q Healthcare Ethics 1994;3:358-66.

10 Lilford R, Van Coerverden deGroot H, Moore P, Gingham P. The relative risks of caesarean section (intrapartum and elective) and vaginal delivery: a detailed analysis to exclude the effects of medical disorders and other acute preexisting physiological disturbances. Br J Obstet Gynaecol 1990;97:883-92

11 Hemminki E, Merilainen J. Long-term effects of cesarean sections: ectopic pregnancies and placental problems. Am J Obstet Gynaecol 1996;174:1569-74

12 Thurmond A, Harvey W, Smith S. Cesarean section scar as a cause of abnormal vaginal bleeding: diagnosis by sonohysterography. J Ultrasound Med 1999;18:13-6, 17-8.

13 Editorial. What is the right number of caesarean sections? Lancet 1997;349(March 22):815.

\section{What is already known on this topic}

Women's preferences for caesarean sections are understood to result from lack of knowledge and psychological aptitude to handle vaginal delivery and its consequences

Efforts to reduce the demand for caesarean sections have focused on providing consumers with correct information on the relative risks associated with vaginal and operative deliveries

\section{What this study adds}

In Brazil, many women prefer caesarean sections because they consider it good quality care

Rich women are more likely to have caesarean sections, supporting the notion that medical intervention represents superior care

Poor women may implement a series of medicalised practices that justifies the need for greater medical intervention during birth

Interventions for reducing caesarean sections by educating physicians and patients about risk factors associated with birthing procedures are not sufficient

14 Peterson-Brown S. Should doctors perform an elective caesarean section on request? $B M J 1998 ; 317: 462-3$.

15 Barros F, Victora C, Vaughan J, Capellari M. Perinatal risk in third world cities. World Health Forum 1985;6:322-4.

16 Cosminsky S. Childbirth and change: a Guatemalan study. In: MacCormack CP, ed. Ethnography of fertility and birth. London: Academic Press, 1982:205-29

17 MacCormack C, ed. Ethnography of fertility and birth. London: Academic Press, 1982.

18 Kaufert P, O’Neil J. Analysis of a dialogue on risks in childbirth: clinicians, epidemiologists, and Inuit women. In: S Lindenbaum ML, ed. Knowledge, power and practice: the anthropology of medicine and everyday life. Berkeley: University of California Press, 1993:32-54.

19 Victora C, Barros F, Vaughan J. Epidemiologia de la desigualdad [Epidemiology of inequality]. Washington DC: Pan-American Health Organization, 1992.

20 Klaus M, Kennell J, Robertson S, Rosa R. Effects of social support during parturition on maternal and infant morbidity. BMJ 1986;293:585-7.

21 Chalmers I, Enkin M, Keirse M. Effective care in pregnancy and childbirth, vol 2. Oxford: Oxford University Press, 1989.

(Accepted 7 November 2001)

\title{
Episiotomy rates in primiparous women in Latin America: hospital based descriptive study
}

Fernando Althabe, José M Belizán, Eduardo Bergel

Current scientific evidence shows that routine episiotomy is not justified: it has no benefit for mother or infant, increases the need for perineal suturing and the risk of complications to the healing process at seven days post partum, produces unnecessary pain and discomfort, and has potentially harmful long term effects. ${ }^{1-3}$ We report rates of episiotomy in primiparous women in Latin American hospitals according to characteristics of hospitals and caregivers.

\section{Participants, methods, and results}

We conducted a hospital based descriptive study based on data routinely collected in a perinatal information system. ${ }^{4}$ We analysed data from 122 hospitals in 16 Latin
American countries that had reported 416852 deliveries between 1995 and 1998. We selected hospitals reporting more than 35 spontaneous vaginal deliveries in primiparous women, which is the sample size required to give a $95 \%$ confidence interval of $10 \%$ either way for an episiotomy rate of $90 \%$. This selection comprised 105 hospitals in 14 countries, which reported 94472 spontaneous vaginal deliveries in primiparous women. We report episiotomy rates by hospital, with medians (interquartile ranges) as a summary measure.

In 91 hospitals (87\%) episiotomy rates were higher than $80 \%$ and in 69 hospitals $(66 \%)$ they were higher than $90 \%$. The overall median rate was $92.3 \%$, and median rates by country varied between $69.2 \%$ and $96.2 \%$ (table). Episiotomy rates were similar in primary, 
Latin American Center for Perinatology, Pan American Health Organization, World Health Organization, Casilla de Correos 627, Montevideo 11000 , Uruguay Fernando Althabe researcher in perinatology José M Belizán director

Eduardo Bergel epidemiologist

Episiotomy rates in primiparous women with spontaneous vaginal deliveries in Latin America, 1995-98

\begin{tabular}{|c|c|c|c|c|}
\hline \multirow[b]{2}{*}{ Location } & \multirow[b]{2}{*}{ No of hospitals } & \multicolumn{2}{|c|}{ No of deliveries } & \multirow[b]{2}{*}{ Median rate (interquartile range) of episiotomies (\%) } \\
\hline & & Total & Median & \\
\hline Mexico & 2 & 1375 & 688 & $69.2(45.7-92.7)$ \\
\hline Panama & 1 & 55 & 55 & 81.8 \\
\hline Argentina & 36 & 32454 & 354 & $85.7(78.7-91.3)$ \\
\hline Colombia & 3 & 3496 & 1314 & $86.2(85.7-88.5)$ \\
\hline Nicaragua & 1 & 146 & 146 & 86.3 \\
\hline Honduras & 2 & 888 & 444 & $92.0(90.7-93.2)$ \\
\hline Brasil & 3 & 406 & 123 & $94.2(47.2-98.9)$ \\
\hline Peru & 9 & 7134 & 918 & $94.4(93.1-94.8)$ \\
\hline Dominican Republic & 1 & 5368 & 5368 & 94.9 \\
\hline Uruguay & 38 & 31456 & 403 & $95.1(93.3-96.4)$ \\
\hline
\end{tabular}

secondary, and tertiary hospitals $(89.8 \%, 91.6 \%$, and $92.7 \%$, respectively) and for public, private, and social security hospitals $(90.2 \%, 96.4 \%$, and $95.6 \%$, respectively). The rates were also similar according to who attended the delivery (doctors in 91.4\%, midwives or nurses in 93.6\%, and students in 93.7\%).

\section{Comment}

Nine in every 10 primiparous women who gave birth spontaneously in hospitals in Latin America between 1995 and 1998 had an episiotomy. This figure was similar in public and private hospitals, primary care and referral hospitals, and deliveries attended by doctors or midwives. If a rate of $92 \%$ is applied to the 2.35 million primiparous women giving birth spontaneously in Latin American hospitals per year, this means that 2.17 million primiparous women per year receive an episiotomy.

The results were obtained from a database in which routine data are collected, and therefore have some potential limitations. The rates might have been affected by different outcome definitions among hospitals, but in maternity health services, episiotomy has a unique definition. In view of the high rates, it is possible that episiotomy rates are over-reported by recording perineal tears as episiotomies. But this is unlikely in the perinatal information system, because outcomes are marked separately in the data collection form. The rate of missing values in this dataset was below $1 \%$.

Seventy one per cent of hospitals in the database were located in Argentina and Uruguay. The results might therefore represent standards of care in hospitals in those two countries rather than elsewhere. The similarities between hospitals in rates of episiotomy are, however, unlikely to be indicative of bias in hospital selection but of a common standard practice in the use of the procedure in most of Latin America's hospitals.

This situation is inadmissible in the light of the current evidence. The challenge now is to design and test an original intervention directed to women and caregivers to change the use of episiotomy in Latin American hospitals.

We thank all health workers and health related workers in many settings of Latin America and the Caribbean for their efforts to collect and send the data from the perinatal information system.

Contributors: FA and JMB participated in the design, execution, and analysis of the study. EB participated in the analysis of the study. The manuscript was prepared by FA, JMB, and EB. Roberto Porro and Luis Mainero provided technical assistance with the perinatal information system database. FA is the guarantor.

Funding: Latin American Center for Perinatology, Pan American Health Organization, World Health Organization.

Competing interests: None declared.

1 Carroli G, Belizan J. Episiotomy for vaginal birth. Cochrane Database Syst Rev 2000;(2):CD000081.

2 Woolley RJ. Benefits and risks of episiotomy: a review of the English-language literature since 1980. Part II. Obstet Gynecol Surv 1995;50:821-35.

3 Signorello LB, Harlow BL, Chekos AK, Repke JT. Midline episiotomy and anal incontinence: retrospective cohort study. BMJ 2000;320: 86-90.

4 Schwarcz R, Díaz AG, Fescina R, Díaz JL, Martell M, Simini F. The perinatal information system. I: the simplified perinatal clinical record. J Perinat Med 1987;15(suppl 1):9.

(Accepted 6 December 2001)

\section{One hundred years ago Advertising}

One last word on the question which lies at the root of this matter-that of the medical etiquette which forbids the recommending of a doctor save by another medical man. On this point, Sir, I know I cannot expect to obtain the agreement of a medical journal-ex officio, you are bound to be against me; but you have many lay as well as professional readers, and to them I would say, Can you honestly say that it is not for the public interest, not for the greatest good of the greatest number, that information should be obtainable by uninstructed persons as to who are leading specialists, or, in the ordinary phrase, the "best people to go to," in this or that medical emergency-I will not even say the best, but good people? To whom could such information do harm? And is it not the case that the single argument against it is the unworthy argument above commented on-the argument that such information might not be unprejudiced. That, Sir, can be urged against every kind of information whatsoever which is given to the public.

(BMJ 1902;i:486) 